\title{
IMPACT OF PHARMACIST INTERVENTION ON MEDICATION KNOWLEDGE AND ADHERENCE IN HEMODIALYSIS PATIENTS
}

\author{
PRUDENCE A. RODRIGUES, AVIN SAJI*, POOJA RAJ, SACHIN SONY
}

Department of Pharmacy Practice, PSG College of Pharmacy, Coimbatore, Tamil Nadu, India

Email: avinsaji94@gmail.com

Received: 12 Dec 2018 Revised and Accepted: 03 Jun 2019

\section{ABSTRACT}

Objective: The objectives of the study are to evaluate the medication knowledge and medication adherence in patients undergoing haemodialysis and to educate the patients regarding the importance of medication adherence through counseling by providing Patient Information Leaflets and to analyze its impact.

Methods: 50 Patients were randomly divided into two groups (control and test). Patient data was collected and documented using the patient data collection form after obtaining their consent. Their knowledge and medication adherence were assessed using questionnaires and was quantified. Patients included in the test group were counseled using Patient Information Leaflets whereas the control group was not counseled. Re-assessment was done during follow up for both groups.

Results: Paired t-test was done to check if there was a significant difference in both the test and control group, with and without the use of Patient Information Leaflets respectively. The study showed that the test group had significant improvement $(\mathrm{P}<0.05)$ in their medication adherence and knowledge whereas there was no significant change in the control group.

Conclusion: Providing patient counseling and continuous education with efforts to improve awareness among haemodialysis patients could enhance adherence to therapies and thus could improve clinical outcomes and quality of life.

Keywords: Intervention, Medication adherence, Knowledge, Haemodialysis, Chronic kidney disease

(c) 2019 The Authors. Published by Innovare Academic Sciences Pvt Ltd. This is an open-access article under the CC BY license (http://creativecommons.org/licenses/by/4.0/) DOI: http://dx.doi.org/10.22159/ijpps.2019v11i7.31305

\section{INTRODUCTION}

Chronic Kidney Disease (CKD) can be defined as the abnormalities of kidney structure or function which is present for $>3 \mathrm{mo}$, with implications for health and which are classified based on cause, glomerular filtration rate (GFR) and albuminuria [1]. Haemodialysis (HD) is a viable, safe and efficient method for the maintenance of patients with CKD progressing to End Stage Renal Disease (ESRD). The patients are dialysed twice or three times per week for approximately $4 \mathrm{~h}$ per session. Patients on maintenance hemodialysis have a complex drug regimen and may receive around 10-12 medications per day, many of which require multiple doses per day. The WHO (World Health Organization) defines medication adherence as, "the degree to which the person's behavior corresponds with the agreed recommendations from a health care provider" [2]. Adherence is the key link between therapy and outcome in medical care [3]. The medication knowledge of the patient is approximated based on the extent of patient's ability to recall the basic essential information. The medication knowledge of haemodialysis patients is extremely poor especially with respect to the name; indication and dosage regimen of their medication [4]. Hence, continuous education is required for a better understanding of the medications among patients. A clinical pharmacist could play a vital role in educating haemodialysis patients which can have an obvious benefit on therapeutic outcome.

\section{MATERIALS AND METHODS}

The study was conducted in the Department of Nephrology, PSG Hospitals. It was a randomised observational study which was carried out for a period of 6 mo with a sample size of 100 patients (as calculated using the Rao software, with confidence interval of $95 \%$ and $5 \%$ margin of error).

Inclusion criteria:

- Inpatients and outpatients with diagnosis requiring haemodialysis.

- Male and female patients above 18 y of age.
- Patients who are willing to be a part of the study.

Exclusion criteria:

- Pregnant and lactating women.

- Psychiatric patients/mentally instable patients.

- Patients with deafness or visual impairment.

- Patients who cannot understand Tamil or English.

The patients were randomly divided into two groups-Control and test group after obtaining the informed consent. Medication knowledge of the patients in both groups was assessed using patient knowledge assessment questionnaire. Medication adherence of the haemodialysis patients were evaluated by Morisky 8 item questionnaire for both the test and control groups [6]. Patients in the test group were educated and counseled using Patient Information Leaflet. Re-assessment of the medication knowledge and the adherence were done after two months for both groups.

\section{RESULTS}

A total of 100 patients were involved in the study on the basis of the inclusion and exclusion criteria. The collected data was analysed using Statistical Package for the Social Sciences (SPSS) 19.0 Version. Numeric variables were compared by student $t$ test. The correlation was analyzed by using chi square. The results were expressed in percentage and mean \pm Standard Deviation (SD). The statistical significance was taken at $95 \%$ confidence interval $(\mathrm{p}<0.05)$.

\section{T-Test (Medication knowledge)}

Comparison of pre and post medication knowledge scores in test group

$P$ value lesser than 0.05 indicates that there is significant difference between the means of the two groups thereby indicating that absence of pharmacist intervention caused no significant change in the patient knowledge. 
Table 1: Comparison of pre and post medication knowledge scores in the test group

\begin{tabular}{llllll}
\hline & & \multicolumn{3}{c}{ Paired samples statistics } \\
\hline & & Mean & N & Std. Deviation & Std. Error Mean \\
\hline Pair 1 & pre & 2.6200 & 50 & 1.48310 & .20974 \\
& post & 4.5400 & 50 & .93044 & .13158 \\
\hline
\end{tabular}

Table 2: Student T-test for pre and post medication knowledge scores in the test group

\begin{tabular}{|c|c|c|c|c|c|c|c|c|c|}
\hline \multicolumn{10}{|c|}{ Paired samples test } \\
\hline & & \multicolumn{5}{|c|}{ Paired Differences } & \multirow[t]{3}{*}{$\mathbf{T}$} & \multirow[t]{3}{*}{ df } & \multirow{3}{*}{$\begin{array}{l}\text { Sig. (2- } \\
\text { tailed) }\end{array}$} \\
\hline & & \multirow[t]{2}{*}{ Mean } & \multirow[t]{2}{*}{$\begin{array}{l}\text { Std. } \\
\text { Deviation }\end{array}$} & \multirow[t]{2}{*}{$\begin{array}{l}\text { Std. error } \\
\text { mean }\end{array}$} & \multicolumn{2}{|c|}{$\begin{array}{l}95 \% \text { confidence interval of the } \\
\text { difference }\end{array}$} & & & \\
\hline & & & & & Lower & Upper & & & \\
\hline Pair 1 & pre-post & -1.92000 & 1.65172 & .23359 & -2.38941 & -1.45059 & -8.220 & 49 & .000 \\
\hline
\end{tabular}

$\mathrm{P}<0.05$

Table 3: Comparison of pre and post medication knowledge scores in the control group

\begin{tabular}{llllll}
\hline & & \multicolumn{2}{c}{ Paired samples statistics } & Std. error mean \\
\hline Pair 1 & & Mean & Std. deviation & .19412 \\
& PRE & 2.4400 & 50 & 1.37262 & .19431 \\
& Post & 2.5000 & 50 & 1.37396 & .1961 \\
\hline
\end{tabular}

Table 4: Student T-Test for pre and post medication knowledge scores in the control group

\begin{tabular}{|c|c|c|c|c|c|c|c|c|c|}
\hline \multicolumn{10}{|c|}{ Paired samples test } \\
\hline & & \multicolumn{5}{|c|}{ Paired differences } & \multirow[t]{3}{*}{$\mathbf{t}$} & \multirow[t]{3}{*}{ df } & \multirow{3}{*}{$\begin{array}{l}\text { Sig. (2- } \\
\text { tailed) }\end{array}$} \\
\hline & & \multirow[t]{2}{*}{ Mean } & \multirow[t]{2}{*}{$\begin{array}{l}\text { Std. } \\
\text { deviation }\end{array}$} & \multirow[t]{2}{*}{$\begin{array}{l}\text { Std. error } \\
\text { mean }\end{array}$} & \multicolumn{2}{|c|}{$\begin{array}{l}\text { 95\% Confidence interval of the } \\
\text { difference }\end{array}$} & & & \\
\hline & & & & & Lower & Upper & & & \\
\hline Pair 1 & PRE-POST & -.06000 & .42426 & .06000 & -.18057 & .06057 & -1.000 & 49 & .322 \\
\hline
\end{tabular}

$\mathrm{P}>0.05$

Table 5: Comparison of pre and post medication adherence scores in the test group

\begin{tabular}{llllll}
\hline Paired samples statistics & & & & \\
\hline & & Mean & N & Std. deviation & Std. error mean \\
\hline Pair 1 & PRE & 5.6200 & 50 & 1.75999 & .24890 \\
& POST & 7.0400 & 50 & .42426 & .06000 \\
\hline
\end{tabular}

Table 6: Student T-test for pre and post medication adherence scores in the test group

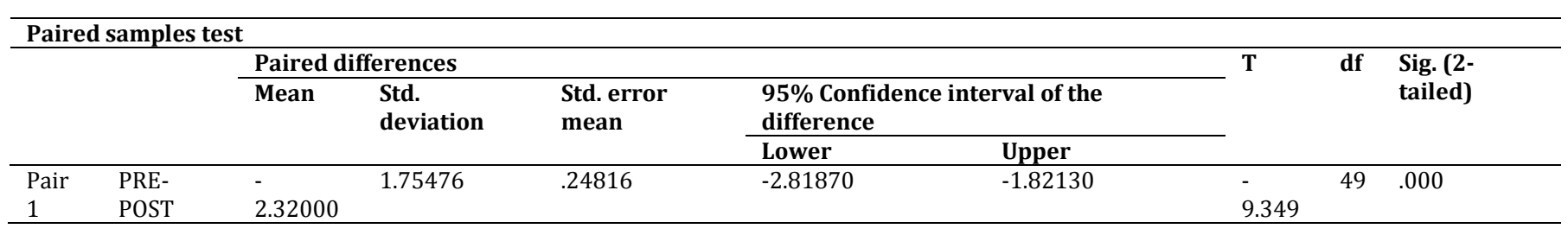

$\mathrm{P}<0.05$

Table 7: Comparison of pre and post medication knowledge scores in the test group

\begin{tabular}{llllll}
\hline \multicolumn{2}{l}{ Paired samples statistics } & & & & \\
\hline & & Mean & N & Std. deviation & Std. error mean \\
\hline Pair 1 & PRE & 5.9680 & 50 & 1.67752 & .23724 \\
& Post & 6.0880 & 50 & 1.66324 & .23522 \\
\hline
\end{tabular}

Table 8: Student T-Test for pre and post medication knowledge scores in the test group

\begin{tabular}{|c|c|c|c|c|c|c|c|c|c|}
\hline \multicolumn{10}{|c|}{ Paired samples test } \\
\hline & & \multicolumn{5}{|c|}{ Paired differences } & \multirow[t]{3}{*}{$\mathbf{T}$} & \multirow[t]{3}{*}{ df } & \multirow[t]{3}{*}{ Sig. (2-tailed) } \\
\hline & & \multirow[t]{2}{*}{ Mean } & \multirow[t]{2}{*}{ Std. deviation } & \multirow[t]{2}{*}{ Std. error mean } & \multicolumn{2}{|c|}{ 95\% Confidence interval of the difference } & & & \\
\hline & & & & & Lower & Upper & & & \\
\hline Pair 1 & $\begin{array}{l}\text { PRE } \\
\text { POST }\end{array}$ & .12000 & .71827 & .10158 & -.32413 & .08413 & -1.181 & 49 & .243 \\
\hline
\end{tabular}

$\mathrm{P}>0.05$ 
Comparison of pre and post medication knowledge scores in control group

$\mathrm{P}$ value greater than 0.05 indicates that there is no significant difference between the means of the two groups thereby indicating that absence of pharmacist intervention caused no significant change in the patient knowledge.

\section{T-Test (Medication adherence)}

\section{Comparison of pre and post medication adherence scores in test group}

$P$ value lesser than 0.05 indicates that there is significant difference between the means of the two groups thereby indicating that the pharmacist intervention caused a significant change in the medication adherence.

\section{Comparison of pre and post medication adherence scores in control group}

$P$ value greater than 0.05 indicates that there is no significant difference between the means of the two groups thereby indicating that absence of pharmacist intervention caused no significant change in the medication adherence.

\section{DISCUSSION}

ESRD is a chronic disease that affects many people all over the world and is associated with high morbidity and mortality [7]. ESRD patients on maintenance haemodialysis, have co morbidities that require multiple medications which may lead to poor adherence [8]. A study by Manan WZ et al. assessed the effect of patient education provided by pharmacists in improving patients' knowledge of their medications and their adherence toward the treatment [9].

The present study assessed the medication knowledge of haemodialysis patients using knowledge assessing questionnaire at the baseline and at review after 2 mo. The knowledge of the participants in the study regarding haemodialysis was found to generally poor which was similar to a study by N. Vanitha Rani et al. which revealed that more than half the participants were lacking basic knowledge regarding medications. The study observed a significant improvement in the medication knowledge of these patients from baseline to the review after continuous education [10].

During the baseline assessment of medication knowledge, some patients had a poor knowledge about the name and strength of the medications given to them and also had a negative belief towards the medication usage as they thought that it was not so important to adhere to the instructions given to them regarding the doses, dosing interval, dosing frequency of the medications they were taking. In this study, prior to patient education sessions, majority of study patients had limited knowledge/poor understanding of the exact role of all the medications they were taking. There was a significant improvement in the medication adherence before $(20 \%)$ and after $(66 \%)$ education in the test group after patient education by the pharmacist which was similar to the study done by N. Vanitha Rani et al. [10]. Research has consistently demonstrated that patients' understanding of their conditions and medications is positively related to adherence [11].

A study done by Kammerer J, et al. had found that the lack of patient education about medications was not an important factor in medication nonadherence but the number of daily medications (typically more than 11) and lack of funds may be the most common reasons [12]. It is also essential to identify other factors leading to poor adherence to medication regimens as it would be beneficial for healthcare professionals to recognize patients who may benefit from interventions to improve medication adherence. This study emphasizes that provision of constant patient education to haemodialysis patients would increase the medication knowledge of the patients and improve their adherence. By making patients understand the significance of the medications being prescribed for them, an increased adherence with long-term medication therapies can be achieved. Emphasis should also be made on the effects of missing medications on the patient's health care outcomes.

\section{CONCLUSION}

In the present study, the impact of structured education showed significant improvement on knowledge about medication adherence in haemodialysis patients. This will improve the awareness of the importance of medications for patients with chronic kidney disease. As per the study results, medication noncompliance was high among the patients studied. Lack of access to medicines remains an important health care problem. The noncompliance associated factors identified in haemodialysis patients were poor knowledge regarding disease condition and therapy. Patient education on medication adherence provided by clinical pharmacists resulted in increasing medication adherence and knowledge at the end of the study. Thus our study shows that efforts to improve awareness on haemodialysis patients such as providing patient counselling and continuous education could enhance adherence to therapies and there by improve clinical outcomes and quality of life.

\section{ACKNOWLEDGEMENT}

Our heartfelt gratitude and deep regards to all teaching and nonteaching staff of PSG College of Pharmacy and the entire health care professional team of nephrology department for extending their timely help and support.

\section{LIMITATIONS OF STUDY}

The major limitation of this study is that it did not assess the association of the factors such as gender, age, duration of dialysis, socioeconomic status and literacy status with medication knowledge and adherence behaviour of the patients.

\section{CONFLICT OF INTERESTS}

Nil

\section{REFERENCES}

1. https://kdigo.org/wp-content/uploads/2017/02/KDIGO2018-Hep-C-GL.pdf [Last accessed on 05 Nov 2018]

2. Jimmy B, Jose J. Patient medication adherence: measures in daily practice. Oman Med J 2011;26:155.

3. Fredric 0 Finkelstein, Kenneth Story. Perceived knowledge among patients cared for by nephrologists about chronic kidney disease and end-stage renal disease therapies. Kidney Int 2008;74:1178-84.

4. Makaryus AN, Friedman EA. Patients' understanding of their treatment plans and diagnosis at discharge. InMayo Clin Proceed 2005;80:991-4.

5. Gibbs S, Waters WE, George CF. The benefits of prescription information leaflets . British J Clin Pharmacol 1989;27:723-39.

6. hpcare.taiwan-pharma.org.tw/Downloads/Morisky\%20scale1021025.pdf. [Last accessed on 05 Nov 2018]

7. Webster AC, Nagler EV, Morton RL, Masson P. Chronic kidney disease. Lancet 2017;389:1238-52.

8. Chakraborty S, Ghosh S, Banerjea A, De RR, Hazra A, Mandal SK Prescribing patterns of medicines in chronic kidney disease patients on maintenance hemodialysis. Indian J Pharmacol 2016;48:586.

9. Manan WZ, Wei FC, Rahman FA, Ming LC. Pharmaceutical care to improve medication knowledge among patient with chronic kidney disease. J Pharm BioAllied Sci 2016;8:263.

10. N Vanitha Rani S. Impact of clinical pharmacist provided education on medication knowledge and adherence of haemodialysis patients in south Indian university hospital. Asian J Pharm Clin Res 2013;6:24-7.

11. Burgoon JK, Pfau M, Parrott R, Birk T, Coker R, Burgoon M. Relational communication, satisfaction, compliance gaining strategies and compliance in communication between physicians and patients. Communications Monographs 1987;54:307-24.

12. Kammerer J, Garry G, Hartigan M, Carter B, Erlich L. Adherence in patients on dialysis: strategies for success. Nephrol Nursing J 2007;34:479. 